\title{
Pathophysiology of heparan sulphate: many diseases, few drugs
}

\author{
U. Lindahl \& L. Kjellén \\ From the Department of Medical Biochemistry and Microbiology, Uppsala University, Uppsala, Sweden
}

\begin{abstract}
Lindahl U, Kjellén L (Uppsala University, Uppsala, Sweden). Pathophysiology of heparan sulphate: many diseases, few drugs. (Review). J Intern Med 2013; 273: 555-571.
\end{abstract}

Heparan sulphate (HS) polysaccharides are covalently attached to the core proteins of various proteoglycans at cell surfaces and in the extracellular matrix. They are composed of alternating units of hexuronic acid and glucosamine, with sulphate substituents in complex and variable yet cell-specific patterns. Whereas HS is produced by virtually all cells in the body, heparin, a highly sulphated HS variant, is confined to connective- tissue-type mast cells. The polysaccharides interact with a multitude of proteins, mainly through ionic binding, and thereby control key processes in development and homoeostasis. Similar interactions also implicate HS in various pathophysiological settings, including cancer, amyloid diseases, infectious diseases, inflammatory conditions and some developmental disorders. Prospects for the development of HS-based drugs, which are still largely unrealized, are discussed.

Keywords: amyloid, cancer, heparanase, heparin, inflammation, malaria, sulphation pattern.

\section{Introduction}

Heparin was discovered almost 100 years ago as an unexpected result of attempts to isolate a bloodprocoagulant phospholipid from dog liver [1]. The resulting product was neither a procoagulant nor a phospholipid but was later identified as a sulphated polysaccharide anticoagulant. Pioneering efforts by Swedish and Canadian groups, headed by Erik Jorpes and Charles Best, respectively, introduced heparin as an antithrombotic drug [2] and modified heparin variants of reduced molecular weight still remain the drug of choice in prophylaxis against postoperative thromboembolic complications [3]. Current annual world production, largely based on pig intestinal mucosa as the starting material, exceeds 30 tons. Heparan sulphate (HS) was initially recognized as a low-sulphated by-product that needed to be removed in the course of heparin manufacture. However, Jorpes and Gardell defined HS as a distinct molecular entity as early as 1948, and more recent work established that heparin is merely one member of the vast HS family of glycosaminoglycans (GAGs) [2]. In fact, whereas heparin is confined to connective-tissue-type mast cells, HSs are produced by most cells throughout the animal kingdom down to comparatively simple organisms [4].

For almost 50 years, our laboratory has been committed to elucidating the structural features of HS-related GAGs, as well as the biosynthetic reactions leading to their formation. Results point to extensive yet strictly regulated structural diversity [5,6]. Parallel studies have revealed that HS species bind a multitude of proteins, mainly through interactions of negatively charged carboxyl and sulphate groups with basic amino acid residues. The interactions profoundly influence important processes in development, homoeostasis and disease [7-10]. Moreover, indirect observations point to HS as a major protagonist in pathophysiological settings that are still only partly understood. This review provides some insight into the multiple roles of HS in various established and some conceivable but as yet undefined disease conditions and reviews potential HS-related drug applications. Examples selected focus primarily on different aspects of HS pathophysiology and are not meant to provide a comprehensive account of relevant clinical conditions.

\section{Basic findings \\ Biosynthesis and structure of heparin/HS}

Structures of HS-related GAGs are best understood in terms of their biosynthesis in the Golgi compartment of cells (Fig. 1a) [11,12]. Selected core proteins are used as primers for GAG polymerization and modification. The products, proteoglycans 
(PGs), carry HS or heparin GAG chains (Fig. 1b) [13]. The heparin PG serglycin occurs in the granules of connective-tissue-type mast cells, where the high negative charge of the heparin chains facilitates packaging of positively charged mast-cell proteases, histamine and other inflammatory mediators [14]. HSPGs are found on the surface of virtually all cells and in the extracellular matrix/basement membranes outside cells. The two major families of cell-surface HSPGs are the syndecans and the glypicans. The core proteins of syndecans (four distinct species) span the plasma membrane, the cytoplasmic parts interacting with intracellular proteins, whereas the glypicans (six species) are attached to the outer surface of cell membranes through a glycosyl-phosphatidylinositol anchor. The main secreted extracellular HSPGs are perlecan, agrin and collagen XVIII. Compared

(a)

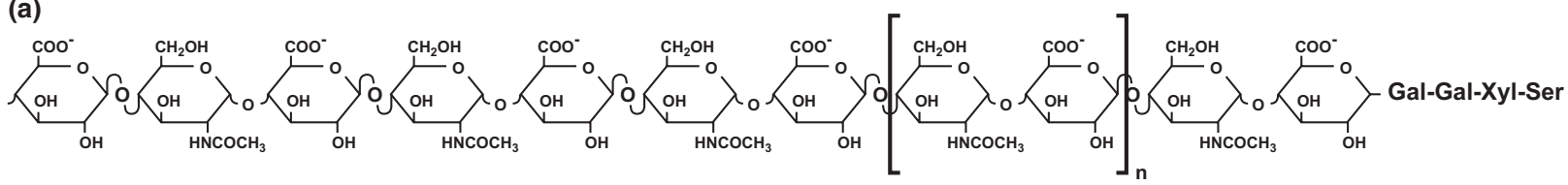
NDSTs

$\underbrace{\mathrm{OH}_{\mathrm{HNCOCH}}}_{\mathrm{OH}^{-}}$ C5-epimerase
2-O-sulfotransferase
6-O-sulfotransferases
3-O-sulfotransferases

$\underbrace{\mathrm{OH}}_{\mathrm{OH}} \mathrm{O}_{\mathrm{HNCOCH}_{3}}^{\mathrm{COO}^{-}}$

WWMWh

(b)

\section{Heparan sulfate-producing cell}

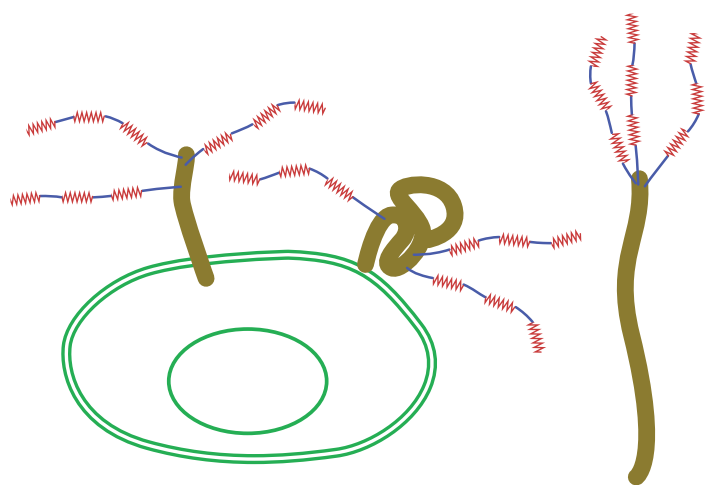

Heparin-producing mast cell

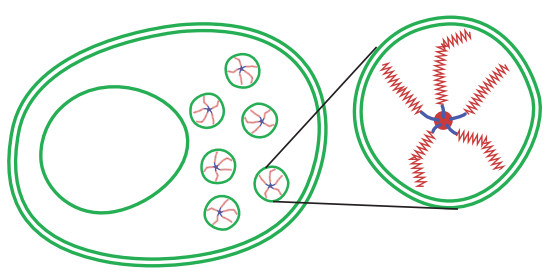


with the vast number of proteins carrying $N$-linked or O-linked oligosaccharides, only a few proteins serve as PG core proteins. Nonetheless, all cells investigated, including red blood cells [15], contain HS (or heparin) PGs.

The formation of HS chains is initiated by the formation of a tetrasaccharide linkage region, synthesized by stepwise addition of xylose, followed by two galactose units and a glucuronic acid residue, from their respective UDP-sugars to a serine residue in the core protein. A fifth enzyme then transfers the first $N$-acetylglucosamine residue to the linkage region, followed by extensive addition of glucuronic acid and $N$-acetylglucosamine units in alternating sequence, which is catalysed by HS-copolymerase (EXT1/EXT2) (Fig. 1a). The nascent GAG chain is modified by sulphotransferases and an epimerase. First, some of the $N$-acetylglucosamine residues are $N$-deacetylated and $N$-sulphated by a dual-activity $N$-deacetylase/ $N$-sulphotransferase (NDST) enzyme, using PAPS (3'-phosphoadenosine-5'-phosphosulphate) as sulphate donor. The partially $N$-sulphated polysaccharide is a substrate for the next modification enzyme, glucuronyl C5-epimerase, which converts glucuronic into iduronic acid residues. Iduronic acid provides flexibility to the polysaccharide chain, facilitating interactions between the GAG and proteins [16]. 2-O-Sulphation locks iduronic acid residues in the interaction-prone configuration. The modification process is completed through 6-O- and 3-O-sulphation of glucosamine units. 2-O-Sulphated or nonsulphated iduronic acid residues, and 6-O-sulphated glucosamines are abundant modification products, whereas 2-O-sulfated glucuronic acid and 3-O-sulphated or $\mathrm{N}$-unsubstituted glucosamine units are scarce
[17]. Notably, completed chains may be further edited through Sulph-catalysed 6-O-desulphation, preferentially of $\mathrm{N}$, 2-O-, 6-O-trisulphated disaccharide units [18]. Whilst C5-epimerase and 2-Osulphotransferase are transcribed from single genes, the other modification enzymes occur as multiple isoforms [19].

Structural complexity and heterogeneity, the hallmarks of HS-related GAGs, are introduced at various levels of the biosynthetic process. Because epimerization and $O$-sulphation occur preferentially in close vicinity to $N$-sulphate groups, $N$ sulphation is a key regulatory step that sets a limit for overall subsequent modification [11,12,20,21]. Heparin features 80-90\% $N$-sulphated glucosamine units and a total $(N-$ and $O-)$ average sulphate content typically greater than two residues per disaccharide unit, whereas HS is 30-60\% $N$-sulphated with a total sulphate content of approximately one residue per disaccharide unit. HS has a characteristic domain structure comprising highly sulphated regions (NS domains) alternating with nonsulphated (NA domains) and mixed (NA/NS) domains [6]. Heparin is more uniformly sulphated and resembles a continuous NS domain (Fig. 1). However, HS species from different sources differ not only regarding size and distribution of the various domains, but also with respect to levels of subsequent modifications within these domains. The modification patterns are cell-specific, such that HS samples from a given murine tissue differ from those of other tissues, but are indistinguishable from corresponding samples isolated from other syngenic mice [5]. Notably, these patterns appear to be largely independent of the core protein type [22]. Obviously, polymer modification is not a random

Fig. 1 (a) Biosynthesis of HS. The process is initiated by the formation of a nonsulphated polymer of alternating glucuronic acid and $\mathrm{N}$-acetylglucosamine units attached to the serine residue of a PG core protein through a galactose-galactosexylose trisaccharide sequence. This precursor polysaccharide undergoes sequential modification steps involving substitution of $N$-sulphate for $N$-acetyl groups ( $N$-sulphation, indicated by grey ellipsoids), C5 epimerization of D-glucuronic to $L$-iduronic acid residues, and sulphation of hydroxyl groups at $C 2$ of iduronic acid (and some glucuronic acid) units, and C6 and $\mathrm{C} 3$ of glucosamine units (O-sulphation, indicated by yellow ellipsoids). The modifications are generally incomplete, such that only a fraction of potential substrate sites are actually targeted. Owing to the substrate specificity of the epimerase and O-sulphotransferases, modifications are essentially restricted to the $N$-sulphated regions of the chains (NS domains, indicated by a zig-zag line under the bottom sequence). Other regions remain largely unmodified (NA domains, straight line). The pentasaccharide structure defined by the horizontal bracket above the bottom sequence binds with high affinity to AT and accounts for the anticoagulant activity of heparin/HS molecules. The various domains rarely exceed 10 sugar units in length, except for the NA domain adjacent to the linkage to protein (16-18 units). (b) Illustration of cell-surface HSPGs (syndecan and glypican) and extracellular HSPG (perlecan), with distribution of NS and NA domains indicated according to the symbols in panel (a). The intracellular serglycin proteoglycans in mast cells carry heparin chains, best envisaged as extended, highly sulphated NS domains. 
process; the question that arises is how it is regulated. Factors of potential importance include expression levels of different enzymes, modulation of their catalytic activities, and the availability of precursor molecules. The activity of an enzyme in a HS-synthesizing Golgi compartment may thus depend on both transcriptional and translational control of expression [23,24], as well as posttranslational modification of the enzyme. Interactions between biosynthesis enzymes have been demonstrated [25-29] and it has been suggested that both elongation and modification of the HS chain take place in so-called GAGosomes [30], molecular complexes of enzymes and other (as yet unidentified) regulatory molecules.

Finally, polysaccharide chain length is another source of heterogeneity. Newly synthesized heparin chains typically fall within the range $60-100 \mathrm{kDa}$ [31], whilst HS chains are shorter $\left(M_{\mathrm{r}}=14\right.$ $45 \mathrm{kDa})[32,33]$. However, even highly purified HS preparations are polydisperse, with a size distribution that varies with the source. Chain size may be established during biosynthesis, but may also reflect endolytic heparanase action. Native heparin chains are generally processed in mast cells by heparanase cleavage, which yields 5 to $25-\mathrm{kDa}$ fragments that are recovered as unfractionated commercial heparin [34]. Notably, the so-called low-molecular-weight heparins $(4-7 \mathrm{kDa})$ that currently dominate clinical practice are generated by chemical or enzymatic cleavage of unfractionated heparin [35]. The smallest and most recently available heparin-related antithrombotic compound is the antithrombin (AT)-binding pentasaccharide (Fig. 1a), obtained through chemical synthesis [36].

\section{Biological functions}

Biological functions of HSPGs generally depend on interactions, mainly electrostatic in nature, with proteins that bind to the sulphated domains of HS chains [10]. The first protein-binding site in a HS chain to be characterized in detail was the ATbinding pentasaccharide sequence in heparin (Fig. 1a). Each of four distinct sulphate groups is essential for productive AT binding, and hence blood anticoagulant activity [16,37]. One of these, a GlcN 3-O-sulphate group, is a rare constituent that was initially believed to be unique to the ATbinding sequence. However, subsequent work showed that 3-O-sulphate groups may be selectively expressed in various HS species and identi- fied a family of 3-O-sulphotransferase isoforms all capable of catalysing specific incorporation of this residue [38]. These findings and other reports of rare sequences raised the notion of selective protein binding dependent on specific sulphation patterns, or a so-called sulphation code [39]. Recent comprehensive studies, however, revealed interactions of highly variable specificity, involving functionally important proteins capable of binding to several polyanionic sequences, provided that these were of sufficient overall charge density $[40,41]$. The highly charged heparin molecule binds a multitude of proteins. However, there are reasons not to simply dismiss such interactions as being merely nonspecific. The strict regulation of HS biosynthesis described previously is likely to control the extent of the various polymer-modification reactions rather than the formation of precisely tailored, minimal-binding sequences towards selected protein ligands. Nevertheless, a sulphation code may apply, in a sense, whenever functional binding requires that selected (preferentially basic) amino-acid residues are targeted by critical sulphate groups (indicated by blue arcs in Fig. 2). A protein-binding sequence would thus contain critical sulphate groups either alone (which is rare) or along with other sulphate groups not essential for (but not interfering with) the interaction. The highly sulphated heparin molecule will therefore express abundant potential proteinbinding sequences. This concept is illustrated in simplified form in Fig. 2. Adding to the complexity is the conformational flexibility of a GAG chain; a defined three-dimensional pattern of critical sulphate groups may conceivably be attained by more than one linear sequence [42]. A 2-O-sulphate group could thus substitute for neighbouring 6-Oor $\mathrm{N}$-sulphate groups, given appropriate adjustments of the chain conformation. Perhaps the 3-Osulphate group, which is rare in general but more frequent in sequences participating in specific interactions, plays a special role; recent NMR results show that a hydrogen bond between the $\mathrm{N}$-sulphate and the adjacent 3-O-sulphate group in the AT-binding pentasaccharide preorganizes the secondary structure in a way that facilitates binding [43].

Several 'heparin-binding' proteins were initially identified without any clue to their functional significance. Further research revealed that the endogenous polysaccharide implicated is generally HS rather than heparin, and many such interactions have now been ascribed functions and phys- 

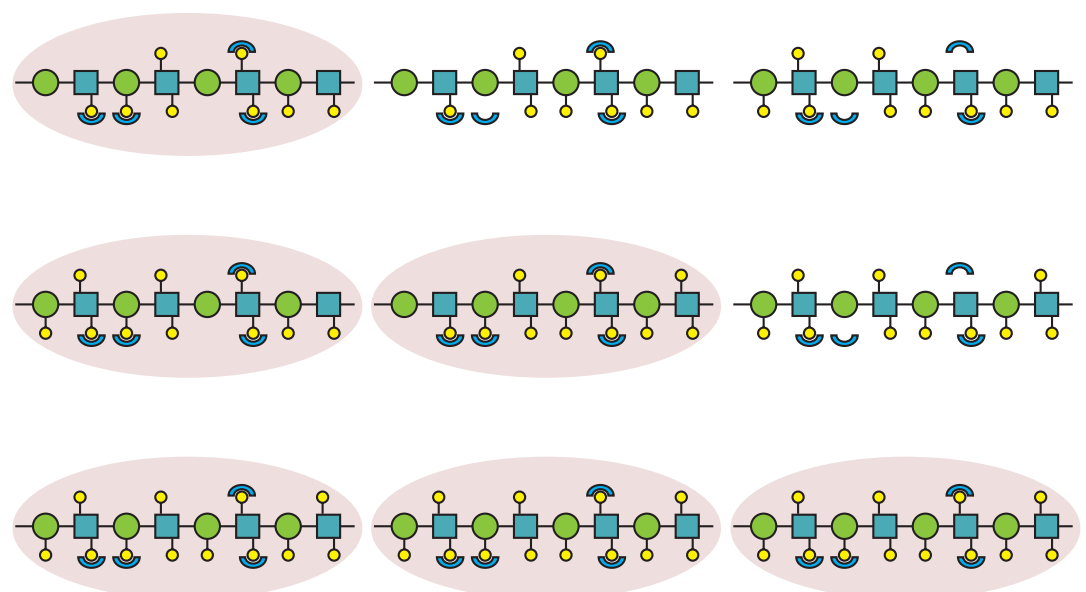

Fig. 2 Schematic illustration of hidden sequence specificity, depending on the defined location of critical sulphate groups (indicated by blue arcs). Only HS domains that accommodate the critical sulphate constellation (enclosed in ellipsoids) promote a functional response in the target protein. The probability of generating such an assemblage increases with the level of sulphation, even given a stochastic distribution of sulphate residues. Fully sulphated heparin-like structures (bottom models) yield maximal productive interactions. For references, see the text.

iological roles [9]. From a mechanistic standpoint, they generally fall into either of two categories [10]. HSPGs may provide scaffolds at cell surfaces or in the extracellular matrix to ensure that proteins committed to specific processes in development or homoeostasis are presented at given sites and times in the body (Fig. 3a). The diversity of protein ligands is striking. HSPGs serve as carriers for enzymes, lipoproteins, chemokines, growth factors and morphogens, with important roles in lipid metabolism, inflammatory processes, angiogenesis and various morphogenetic developmental events. Transient capture of growth factors or morphogens may help to stabilize protein gradients, control the range of signalling, or simply protect the proteins against degradation. Interactions of HSPGs in basement membranes with matrix proteins, such as fibronectin and laminin, provide support, resistance to mechanical stress and filtration barrier properties.

The other major type of HS-protein interaction contributes more directly to biological activities or signalling processes (Fig. 3d) [10]. A well-studied example is the anticoagulant activity of heparin (and some HS species), which is mediated by binding of a specific pentasaccharide species (Fig. 1a) to the protease inhibitor AT. The resultant subtle conformational change turns the AT molecule into a more efficient inhibitor of procoagulant serine proteases [44]. Interactions between HSPGs and a variety of growth factor or morphogens modulate FGF, Hedgehog, TGF- $\beta$, BMP and Wnt signalling [45]. Whereas the precise nature of HS involvement in some of these pathways remains unclear, direct participation of polysaccharide chains in signalling complexes with some cellsurface receptors has been demonstrated $[46,47]$. Further details in connection with specific pathophysiological aspects are discussed below.

\section{Heparanase}

Heparanase was initially recognized for its ability to depolymerize the extended heparin chains of serglycin PG in connective-tissue-type mast cells $[34,48,49]$. A similar endoglucuronidase, capable of depolymerizing HS as well, was found in platelets [50] and subsequently in a variety of tissues. To date, only a single heparanase species has been described [51-53]. The use of transgenic mouse models featuring either overexpression [54] or depletion [55] of the enzyme are discussed below to clarify HS function in various pathophysiological settings.

\section{Pathophysiology}

Interactions between HS and proteins are essential for development and homoeostasis and have been critically implicated in various pathophysiological phenomena. Mice subjected to genetic ablation of HSPG core proteins or HS biosynthetic enzymes display an impressive range of phenotypes, from 
(a)

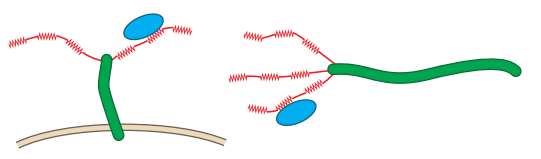

(b)

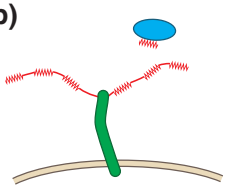

(c)

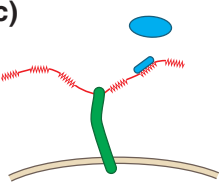

Interaction of proteins with cell-surface or matrix HSPGs

(d)

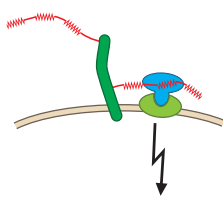

(h)

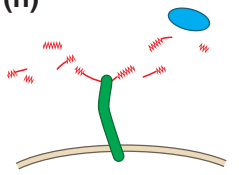

(e)

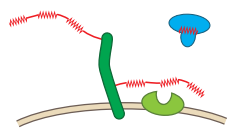

HS in growth-factor signaling (i)

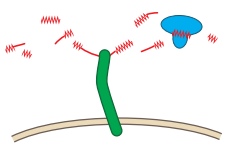

(f)

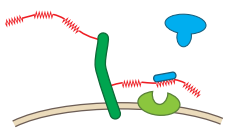

(g)

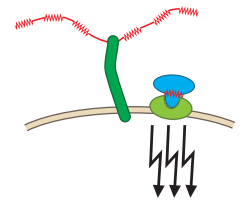

(k)

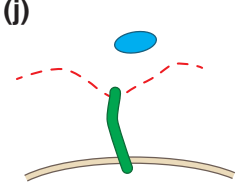

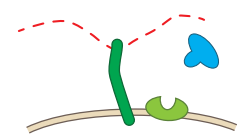

Effects of heparanase

Inhibition of HS biosynthesis

Fig. 3 HS-protein interactions and their inhibition. (a) Proteins bind to HS chains of HSPGs at the cell surface (syndecan depicted) or in the extracellular matrix (perlecan), mainly through electrostatic interaction. (d) HS chains serve as coreceptors for many proteins; the example shown here promotes growth factor action. Interactions may be disrupted by (b, e) competitive saccharides (or mimetics) that block HS-binding sites on target proteins or (c, f) decoy peptides (mimetics) that block protein-binding HS sequences. (g) Authentic or modified HS/heparin fragments may replace endogenous HS and augment protein responses. Fragmentation of HS chains by heparanase may release a ligand, either as (h) a free protein or (i) bound to an oligosaccharide fragment. (j,k) Perturbation of HS-protein interactions resulting from interference with HS biosynthesis. For further information and references, see the text.

early embryonic death to almost imperceptible anomalies. In general, the more severe phenotypes are due to loss of HS chains or major perturbation of HS structure caused by extensive interference with polymer modification. Elimination in mice of either of the two HS-copolymerase enzymes Ext1 and Ext2 (Fig. 1a) leads to severe impairment of chain formation and early embryonic death [56,57]. A similar phenotype is observed when NDST1 and NDST2 are both missing, resulting in the formation of a polysaccharide essentially devoid of sulphation [58]. Embryos deficient in NDST1 alone survive longer but still die either before birth or shortly thereafter due to respiratory failure (along with skeletal and cerebral defects) [59-61]. By contrast, NDST2 ${ }^{-/-}$ mice show defective heparin biosynthesis, and hence abnormal connective-tissue-type mast cells but are otherwise viable and fertile $[62,63]$. Other structural defects, such as loss of iduronic acid $[64,65]$ or 2-O-sulphate groups [66] or partial loss of 6 -O-sulphate groups $[67,68]$, result in phenotypes that may be functionally severe, yet limited to only a few tissues or organ systems. Again, these findings raise the issue of specificity in HS-protein interactions. Knockout of HSPG core proteins also yields highly variable phenotypes, depending on PG type $[69,70]$. In general, these phenotypes are milder than those associated with loss or severe perturbation of HS chains, presumably due to functional redundancy amongst PG species. Notably, however, loss of either perlecan or agrin, both extracellular HSPGs, is incompatible with life. More comprehensive accounts of knockout phenotypes are available in the literature $[9,71]$.

Whereas phenotypes due to genetic manipulation of HSPG biosynthesis may reflect aspects of human disease, most HS-associated pathological conditions involve interactions between GAG chains that are essentially normal and a variety of proteins that may be either normally occurring or disease-specific. We consider such conditions 
primarily according to protein ligands to implicated HSPGs. A few potential links between altered PG expression or HS structure and various pathological states have been explored. Finally, use of heparanase transgenic mouse models has led to intriguing novel insights into HS pathophysiology.

\section{Protein ligands}

\section{Growth factors and morphogens}

Various disease conditions involve aberrant cell signalling of HS-dependent growth factors or morphogens. The development of hereditary multiple exostoses (HME), a basically benign condition involving the long bones, has been linked to dysregulated Indian Hedgehog signalling [72]. HS Sulphdependent Wnt action appears to be augmented in gastric cancer [73]. HSPG modulation of bone morphogenic protein (BMP) signalling has been implicated in fibrodysplasia ossificans progressiva [74].

Tumour-induced neovascularization is a universal feature of solid cancers, and much attention is aimed at developing antiangiogenic drugs [75]. Three growth factors, platelet-derived growth factor (PDGF), fibroblast growth factor 2 (FGF2) and vascular endothelial growth factor (VEGF), all of which signal through tyrosine kinase receptors, have key roles in vascular sprouting and expansion [76]. All three growth factors functionally depend, albeit to variable extent, on interaction with HS [77 -79], although the related polysaccharide, chondroitin sulphate, seems to be able to replace HS and support sprouting angiogenesis [80]. PG coreceptors may be located not only beside the appropriate tyrosine kinase-type receptors at the cell surface, but also in the extracellular matrix [70] or even on adjacent cells [81,82]. Therapeutic approaches include neutralizing antibodies or receptor kinase inhibitors, but the results are so far inconsistent and largely disappointing [76]. HS-growth factor or HS-receptor interactions may be potentially targeted by competing ligands (Fig. 3e,f); indeed, VEGF-induced receptor signalling and vascular hyperpermeability were attenuated by administration of two distinct HS antagonists, protamine and surfen (a small HSbinding molecule) [83]. Beneficial effects of heparin treatment observed for the survival of patients with various forms of cancer may, amongst other possible mechanisms [84], reflect displacement of growth factor(s) from interaction with endogenous HS. Notably, the antiangiogenic polypeptide endostatin binds HS [85] and prevents tumour growth, although the precise mechanism remains unclear.

Recent findings raise novel prospects for HS-based treatments in regenerative medicine. For instance, heparin and HS may be applied in bone regeneration to enhance the biological activity of endogenous or added growth factor at the site of injury. Bone formation induced by bone morphogenic protein-2 (BMP-2) was promoted by a HS species derived from a bone-marrow stromal cell line [86].

\section{Amyloid proteins}

Amyloid diseases are characterized by tissue deposition of proteins prone to aggregate in fibrillar insoluble form. Diseases include severe maladies as diverse as AA amyloidosis, Alzheimer's disease, TTR amyloidosis, type 2 diabetes, Parkinson's disease, amyotrophic lateral sclerosis, prion diseases and AL amyloidosis [87]. The amyloid proteins are structurally unrelated but share the ability to bind HS, which is thus a potential therapeutic target in amyloidogenesis [88]. The apparently invariable occurrence of HSPGs in amyloid deposits is presumably due to the ability of HS chains to promote (or modulate) fibrillogenesis (Fig. 4a) [89-91]. However, detailed analysis of HS association with various amyloid diseases has revealed more diverse involvement, as exemplified in Alzheimer's disease. HS contributed by glial cells is codistributed with $\mathrm{A} \beta$ amyloid peptide in the cerebral senile plaques that are hallmarks of the disease [92]. Moreover, cell-surface HSPG mediates $\mathrm{A} \beta$ internalization and cytotoxicity [93]. By contrast, binding of $\mathrm{HS}$ to $\beta$-secretase (BACE1) restricts proteolytic cleavage of the amyloid precursor protein (APP) and hence the formation of $A \beta$ peptide [94]. These findings point to a need for selective inhibition of HS-protein interactions.

The role of HS-amyloid interactions in pathogenesis of amyloid diseases was underpinned in studies of inflammation-related AA amyloidosis. This severe clinical disorder involves systemic codeposition of the acute phase reactant serum amyloid A (SAA) and HS in various organs. Whereas structural analysis of HS recovered from different amyloid-laden organs indicated amyloid-specific composition [95], the question as to whether accumulation of this HS is due to overproduction of a specific HS species or to selective sequestration by binding to the amyloid remained unresolved. Experimental AA amyloid induction in heparanase-overexpressing mice correlated inver- 
(a)

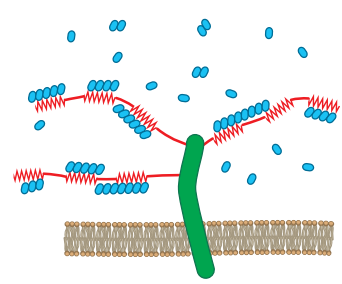

(c)
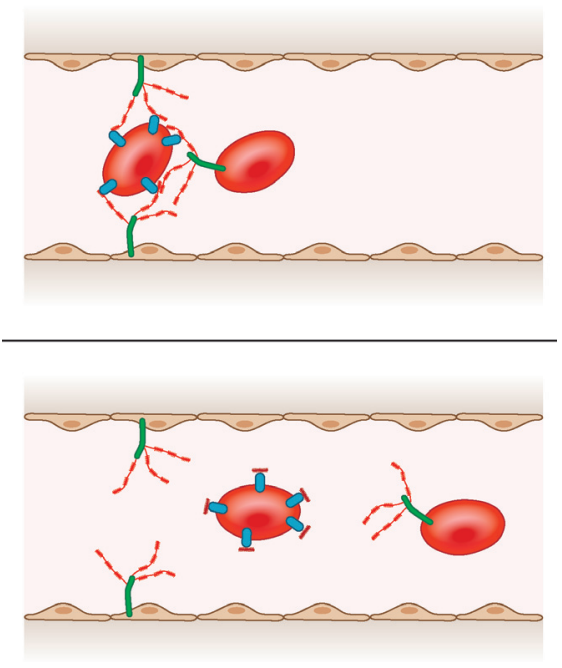

(b)

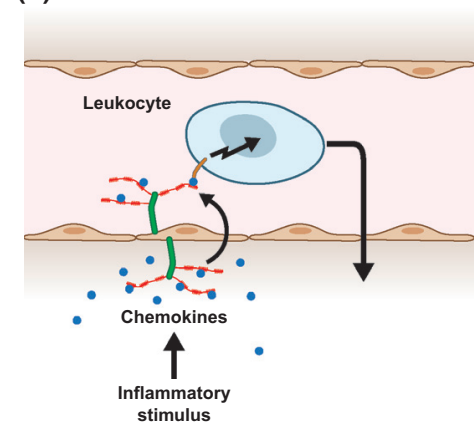

(d)
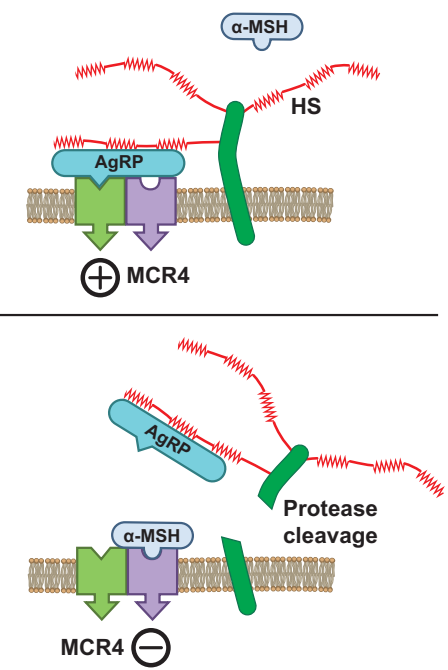

Fig. 4 HSPGs in various pathophysiological settings. (a) Interactions of amyloidogenic peptides with HS chains promote aggregation and amyloid deposition. (b) Role of HSPGs in leukocyte diapedesis. Extravascular chemokines (e.g. CCL2) induced following an inflammatory challenge are captured by HS chains and relayed through transcytosis to the luminal side of the vascular endothelium, where they target cell-surface receptors on leukocytes (e.g. monocytes). The activated cells attach firmly to the endothelium and eventually exit the vessel. (c) Role of vascular HS in rosetting and cytoadherence of erythrocytes in cerebral malaria. Erythrocytes infected by Plasmodium falciparum express surface-attached PfEMP1 protein (blue bars) that interact with HS chains on HSPGs (green core proteins) located on other erythrocytes or on the vascular endothelium (upper scheme). Deactivated heparin fragments (devoid of anticoagulant activity) displace HS by competitive binding, thereby dissolving cell aggregates (lower scheme). (d) Role of hypothalamic cell-surface HSPG (syndecan-3) in regulation of food intake. HS chains serve as coreceptors for agouti-related protein (AgRP) and at the same time preclude access of $\alpha$-melanocyte-stimulating hormone ( $\alpha-M S H)$ to melanocortin receptor 4 (MCR4), resulting in stimulation of appetite. Release of syndecan due to regulated protease cleavage allows binding of $\alpha$-MSH, which induces satiety. For further information and references, see the text.

sely with the level of enzyme overexpression, in apparent accord with the notion that HS chains promote amyloid fibrillogenesis [96]. Thus, liver showing extensive heparanase expression and HS fragmentation [97] was virtually resistant to amyloid deposition (however, see the section on HSlipoprotein interactions below).

\section{Lipoproteins}

Interactions of HSPGs with apolipoproteins and lipolytic enzymes have been implicated in lipoprotein metabolism and associated disease conditions, such as atherosclerosis [98] and Alzheimer's disease [99]. Of particular interest was the finding that hepatocyte HS directly mediates clearance of 
triglyceride-rich lipoproteins in mice, independently of any LDL receptor [100,101]. It was concluded that HSPGs play a crucial role under normal physiological conditions in the clearance of both intestinally derived and hepatic lipoprotein particles. It was also suggested that aberrant expression of liver HS could be one cause of triglyceride accumulation in diabetes and possibly other disorders.

Recent analysis of pathogenesis in AA amyloidosis led to a novel mechanistic insight. The amyloid precursor SAA is normally associated with the high-density lipoprotein (HDL) fraction in plasma. Noborn et al. [102] showed that HS dissociates SAA from HDL by simultaneously binding SAA and another HDL apolipoprotein, ApoA-I, thereby providing free SAA available for amyloid conversion. The process requires a minimum saccharide chain length of 12-15 units and would thus be compromised by extensive HS fragmentation. These findings provide an alternative explanation of the amyloid-attenuating effect of heparanase overexpression already discussed [96].

\section{Inflammatory proteins}

Several families of proteins, including selectins and chemokines, have key functions in inflammatory reactions that are variously influenced by heparinrelated GAGs. The primary common function of these proteins is control of the localization and migration of various types of immune cells (Fig. 4b) [103]. Interactions of various chemokines with cellsurface HS have been elucidated in molecular detail. Notably, chemokine function depends on binding to HS chains with adequately spaced sulphated domains, which is required to cover separate clusters of basic amino-acid residues in a chemokine monomer $[104,105]$ or to support oligomerization of the protein $[106,107]$. Chemokine binding to $\mathrm{HS}$ ensures appropriate positioning within tissues and maintenance of haptotactic gradients to direct cell migration. Moreover, HSprotein interactions support several steps of the inflammatory process. Vascular endothelial HS acts as a ligand for L-selectin during neutrophil rolling, supports chemokine transcytosis and presents chemokines at the lumenal surface of the endothelium [108].

Interactions between HS and selectins or chemokines have been implicated in diverse disease settings. Attenuation of cancer metastasis during heparin treatment has been ascribed in part to displacement of bound L-selectin from endogenous HS (Fig. 3b) [109]. Weakening of neuroinflammation in transgenic mice overexpressing heparanase was ascribed to perturbed HS-chemokine interaction (Fig. 3h) resulting in inhibited recruitment of bloodborne monocytes [110]. Beneficial effects of heparin treatment have been noted in other inflammatory conditions, such as lipopolysaccharideinduced acute lung injury [111] and inflammatory bowel disease [112].

\section{Microbial proteins}

To gain entry into the host, viruses use host cellsurface molecules that normally serve as receptors for other ligands. Various viral-docking proteins utilize HSPGs on host cells as receptors or coreceptors [113], including pseudorabies virus gC protein [114], herpes simplex gC and gD proteins [115,116] and human papilloma virus L1 capsid protein [117]. Specific drug targeting (with an $N, N^{\prime}$-bisheteryl derivative of dispirotripiperazine) of cell-surface HS moieties prevents infection by various viruses [118]. HS also binds HIV-1 transactivating factor Tat, which reveals a novel mechanism for lymphocyte adhesion and migration across the endothelium in response to chemokine signalling. These findings afford a new insight regarding extravasation of lymphoid cells during HIV infection [119].

Following the initial identification of cell-surface HS as a (co)receptor for herpes simplex virions $[120,121]$, the relationship unfolded through intrinsically different approaches. Genetic rescue experiments restored viral-binding ability as well as HS biosynthesis in cells defective in EXT1, previously recognized as a tumour suppressor (see the section on HME below) [122]. The effect of EXT1 on HS biosynthesis was explained when the closely related protein EXT2 and EXT1 were shown to possess both GlcA- and GlcNAc-transferase activities required to generate the initial polysaccharide backbone [122,123]. The EXT1-EXT2 complex is now perceived as the HS copolymerase complex (see the section on HS biosynthesis). Meanwhile, gC affinity chromatography of oligosaccharides from authentic HSs or partly desulphated heparin revealed a minimal gC-binding sequence of approximately 10 monosaccharide units, containing 2-O- and 6-O-sulphate groups within N-sulphated domains [115]. Unexpectedly, enzymatic incorporation of a $\mathrm{GlcN} 3-\mathrm{O}$-sulphate group into HS generated a gD-binding domain conducive to viral entry [116]. The enzyme was one of multiple GlcN 3-O-sulphotransferase isoforms, distinct from 
that previously shown to catalyse 3-O-sulphation of the AT-binding region in heparin and HS (Fig. 1a; this structure differs from that of the gD-binding domain) [124]. A 3-O-sulphated octasaccharide generated through chemoenzymatic synthesis inhibited viral entry into target cells to a greater extent than the non-3-O-sulphated analogue [125].

In Plasmodium falciparum malaria, a condition that is particularly serious in children, severe anaemia, respiratory distress and cerebral ischaemia are common. These states largely result from excessive binding of parasite-infected erythrocytes to the vascular endothelium (cytoadherence) and to other infected and uninfected erythrocytes (rosetting). The sequestration of cells may lead to occlusion of the microvasculature, a direct cause of cerebral ischaemia associated with high mortality [126]. The apparent resemblance to a thrombotic disorder led to treatment with heparin that was in part successful, but occasionally complicated by intracranial bleeding, so it was therefore abandoned [127]. However, more recent studies revealed that the condition is not a coagulopathy but is due to interaction between $P$. falciparum erythrocyte membrane protein 1 (PfEMP1), a parasite-derived molecule present at the surface of infected erythrocytes, and host receptors on endothelial and red blood cells [128]. The host receptors on endothelium and erythrocytes were identified as cell-surface HS [15] and the previously observed effect of heparin treatment could thus be ascribed to blocking of PfEMP1-HS interaction (Fig. 4c). Binding of PfEMP1 requires $\geq 12$ mers of $\mathrm{HS}$ (or heparin) containing $\mathrm{N}$ - and 2 - and 6-O-sulphate groups, but no AT-binding domain, raising the prospect of generating a heparin-derived PfEMP1 blocking agent devoid of anticoagulant activity. Such a product was achieved by selective periodate oxidation of heparin, which resulted in cleavage of the glucuronic acid residue occurring in the AT-binding pentasaccharide sequence (Fig. 1a). Such deactivated products reproduced the effects of heparin, inhibiting both rosette formation and cytoadherence to the vascular endothelium, which suggests that they may be candidates for adjunct therapy in severe malaria [126].

Bacterial M protein, a classical virulence determinant, is a powerful inducer of inflammation. Inflammatory plasma leakage, which can potentially lead to toxic shock, is caused by a cationic heparinbinding protein released by neutrophils on challenge by $M$ protein [129]. The heparin-binding protein presumably interacts with HSPGs at the vascular endothelial surface and thus induces rearrangement of the cytoskeleton and the formation of intercellular gaps [130,131]. This mechanism may in part explain the antimicrobial properties expressed by HS/heparin-binding peptides from various sources (as illustrated in Fig. 3f) [132].

\section{Altered HSPG expression or structure}

\section{Core proteins}

Various pathological conditions have been ascribed to deficiency of HSPG core proteins. Loss-of-function mutations of glypican-3 cause Simpson-Golabi-Behmel syndrome, a paediatric condition characterized by somatic overgrowth [133]. Recessive omodysplasia, characterized by short limb stature and craniofacial dysmorphism, has been linked to mutations in glypican-6 that entail loss of the GPI anchor and the HS attachment sites [134]. By contrast, augmented expression of glypican-5 increases the risk of acquired nephrotic syndrome [135]. Complete loss of perlecan leads to dyssegmental dysplasia of the Silverman-Handmaker type $[136,137]$, whereas Schwartz-Jampel syndrome is caused by mutations in the perlecan core protein [138]. Whilst dyssegmental dysplasia is a form of lethal dwarfism, Schwartz-Jampel syndrome is milder and characterized by myotonia and chondrodysplasia. Congenital myasthenia was ascribed to a mutation in the extracellular HSPG agrin, which leads to perturbation of the neuromuscular junction [139]. The autosomal recessive Knobloch syndrome, characterized by occipital encephalocele and visual impairment, is caused by mutations in collagen XVIII [140].

Prolonged labour is associated with decreased expression of syndecan-3 in human uterine tissue [141]. The precise mechanism is unclear. However, potential clues emerged from the unexpected finding that women treated with low-molecular-weight heparin during pregnancy had significantly shorter labour times compared with untreated women [142]. A search for the mechanism(s) revealed augmented IL- 8 secretion by heparin-treated fibroblasts cultured from explants of cervical biopsies obtained at delivery, suggesting an effect on cervical ripening. Moreover, myometrial smooth-muscle strips pretreated with low-molecular-weight heparin showed increased contractile activity in response to oxytocin stimulation, pointing to an effect of heparin on the oxytocin signalling 
pathway. These findings raise intriguing questions regarding the role of endogenous HS in delivery, in particular, HS chain substitution of syndecan-3.

\section{HS chains}

Mucopolysaccharidosis diseases are caused by mutations of genes encoding degradative enzymes required for turnover and elimination of GAG chains. Defects in enzymes involved in HS degradation give rise to a number of rare diseases of varying severity, characterized by excessive organ storage of partially degraded HS. A promising method for diagnosing these diseases based on characterization of the unique mono-, di-, or trisaccharide units in the nonreducing ends of the accumulated GAGs was recently published [143]. Unexpectedly, HS biosynthesis in afflicted cells also seems to be affected by accumulated GAGs [144]. The genetics, enzymology and clinical aspects of these conditions have been the subject of several reviews [145-147] and are not further discussed here.

Given the large number of phenotypic aberrations resulting from genetic manipulation of HS biosynthetic enzymes in model organisms [9], surprisingly few human disease conditions have been primarily ascribed to deranged HS biosynthesis. However, changes in HS structure may be secondary to other disease manifestations, such as the upregulated sulphation of HS associated with tumour-induced heparanase overexpression [97] or decreased $\mathrm{N}$-deacetylation/ $\mathrm{N}$-sulphation in experimentally induced diabetes [148]. Nevertheless, syndromes attributed to mutations of genes encoding HS biosynthetic enzymes are slowly growing in number. Multiple hereditary exostoses (HME) is caused by haploinsufficiency of either of the EXT1 and EXT2 proteins that comprise the Golgi-associated HS polymerases (Fig. 1a) [149]. Ext1 mouse-mutant fibroblasts, expressing only low levels of the enzyme, produced shorter HS chains than wild-type control cells, responded poorly to FGF2 stimulation and showed reduced ability to attach to collagen I [150]. Defective HS generation is a probable cause of the dysregulation of Indian Hedgehog signalling implicated in HME [72]. Interestingly, conditional inactivation of EXT1 in postnatal neurons had no detectable effect on brain morphology in mice, but induced almost the full range of symptoms typical of human autism (impairment of social interaction, stereotype repetitive behaviour, etc.) [151]. Another syndrome caused by neural dysfunction, idiopathic gonadotrophic hypogonadism, was recently associated with mutations in the HS 6-O-sulphotransferase-1 gene [152]. We also note, however, that deranged HS structure in vivo caused by genetic ablation of biosynthetic enzymes is not invariably associated with a predicted phenotype. Thus, contrary to expectation, loss of an AT-binding sequence in vascular $\mathrm{HS}$ due to elimination of 3-O-sulphotransferase- 1 in mice did not lead to any thrombotic disorder [153]. In fact, the AT-binding sequence is much more abundant in mast-cell heparin, and it has been suggested that its major functional role lies in control of extravascular coagulation induced by inflammatory macrophages [154].

\section{Heparanase pathophysiology}

Tumour growth and metastasis are closely intertwined with heparanase overexpression, which confers an invasive phenotype in experimental animals. The enzyme releases HS-bound angiogenic factors from the extracellular matrix (Fig. 3i), thereby inducing an angiogenic response in vivo. Heparanase upregulation correlates with increased tumour vascularity and poor postoperative survival of patients with cancer [52]. The enzyme further promotes metastasis by degrading HSPGs in basement membranes, facilitating passage of tumour cells through the vascular wall. Degradation of HS in the glomerular basement membrane contributes to diabetic nephropathy, proteinuria and kidney dysfunction. Heparanase also appears to be causally involved in inflammation and is dramatically upregulated in autoimmune diseases such as inflammatory bowel disease [155], rheumatoid arthritis (but not osteoarthritis) [156] and type 1 diabetes [157]. Interpretation of these findings is not entirely straightforward. Overexpression of heparanase attenuated neuroinflammation induced by localized cerebral microinjection of $A \beta$ amyloid aggregates in mice. Compared to wild-type mice, the transgenic animals displayed impaired macrophage-mediated elimination of the aggregates; this defect is due to a perturbed ability to recruit monocytes across the blood-brain barrier [110]; see also the section on Inflammatory proteins above. Can heparanase overexpression be part of defence mechanisms in Alzheimer's disease or other conditions involving inflammatory reactions?

The recent availability of heparanase knockout mice has revealed novel roles for heparanase in modulating interactions between heparin/HS and selected proteins. Cultured foetal skin-derived murine mast 
cells lacking heparanase contained longer heparin chains than control cells, but more proteases stored in cytoplasmic granules. Conversely, heparanaseoverexpressing cells showed shorter heparin chains and significantly less proteases, apparently due to spontaneous release of granular material. It was concluded that heparanase functions in maintaining mast-cell homoeostasis [53].

Heparanase-deficient mice show maturity-onset obesity, whereas heparanase-overexpressing mice have reduced body fat [158]. An explanation was based on previous findings of obesity induced by transgenic overexpression of syndecan- 1 in mice [159]. This earlier study uncovered physiological control of feeding behaviour by syndecan-3, the HS chains of which stimulate appetite by promoting signalling of agouti-related protein, a primary agonist of hypothalamic melanocortin receptor 4 . Release of syndecan-3 ectodomain by satietyinduced protease cleavage instead provides access for the appetite-depressing reverse agonist $\alpha$-melanocyte-stimulating hormone. Because transgenic syndecan-1 lacks the protease cleavage site of syndecan-3, the receptor persistently signalled hunger (Fig. 4d). Heparanase-deficient mice ate more than control mice, whereas local intracerebroventricular microinjection of heparanase decreased appetite [158]. It was proposed that heparanase participates in appetite regulation by cleavage of HS chains at the melanocortin receptor 4 and through peripheral effects on energy metabolism.

\section{Concepts for drug design?}

The only heparin-/HS-related bioactivity exploited in routine clinical application is anticoagulant/ antithrombotic activity. However, the pivotal roles of HS-protein interactions in different pathophysiological settings, only some of which have been reviewed here, suggest the use of drugs that could either potentiate or, more likely, disrupt the associated biological activities. Figure 3 shows various options, some of which have been discussed in a previous review [160].

Potentiation of a biological activity normally exerted through heparin or HS (Fig. 3g, illustrating growthfactor activity) has been demonstrated for synthetic mimetics of the AT-binding pentasaccharide. Various developments of this concept to induce neutralizability and to confer favourable pharmacokinetic properties to other saccharide-linked drugs have been described [161]. HS mimetic oligosaccharides have been generated to mobilize hematopoietic progenitor cells, which are of importance in haematopoietic stem cell transplantation [162]. Similar developments may be anticipated in other clinical settings, such as wound healing.

The major potential for HS-related drugs is to prevent or weaken HS-protein interactions. Several strategies have been proposed. General inhibition of HS biosynthesis may seem an adventurous aim given the diverse roles of HS in homoeostasis but is nevertheless worthy of consideration (Fig. 3j,k). Variously substituted xylosides have been used as competitive inhibitors of xylosyltransferase, which initiates polysaccharide substitution on PG core proteins, in cancer therapy, along with inhibitors of polyamine biosynthesis [163]. Formation of the HS precursor polysaccharide can also be inhibited by glucosamine analogues, which are under consideration for treatment of various amyloid diseases [164]. Direct, albeit nonselective, inhibition of HS-protein interactions may be achieved using small-molecule antagonists, such as surfen (bis-2-methyl-4-amino-quinolyl-6-carbamide) [165] and anionic sulphonates [166]. A recent report described a strategy based on engineered mutagenesis for generating decoy protein ligands potentially capable of selective blocking of GAG sequences (Fig. 3c,f) [167].

Competitive saccharide ligands offer a logical approach for targeting of HS-protein interactions (Fig. $3 \mathrm{~b}, \mathrm{e})$. The rationale is based on the unexpected beneficial effects of heparin treatment in various disease conditions, as described in previous sections. Displacement of a protein from its endogenous HS ligand by heparin is often considered a nonspecific phenomenon, ascribed to the exceptional polyelectrolyte properties of the polysaccharide. Whilst this notion may well apply in some cases, the concept of 'hidden specificity' should be kept in mind, as discussed previously. Heparin, which is highly sulphated, is likely to provide the critical sulphate groups required to interact with key basic amino acids in a target protein that binds to HS in a more selective manner (Fig. 2). To generate a selective oligosaccharide ligand (or mimetic), it will be necessary to pinpoint the sulphate groups that are functionally essential. A rational approach to such analysis requires access to arrays of HS-related oligosaccharides with systematically varied locations of sulphate substituents [168]. It is hoped that such reagents will be available in the near future. 
Finally, the detrimental effects of heparanase in various conditions, and in cancer in particular, call for efficient inhibition of the enzyme. Such drugs have been generated by selective desulphation of heparin followed by glycol splitting of pre-existing or chemically generated nonsulphated uronic acid residues [169] and by sulphation of mannose oligosaccharides [170]. It should be noted that such drugs would be contraindicated in conditions in which heparanase overexpression is actually beneficial.

\section{Conflict of interest statement}

Noconflict of interest todeclared.

\section{References}

1 McLean J. The thromboplastic action of cephalin. Am J Physiol 1916,41:250-7.

2 Roden L, Ananth S, Campbell P et al. Heparin-an introduction. Adv Exp Med Biol 1992; 313: 1-20.

3 Gresele P, Busti C, Paganelli G. Heparin in the prophylaxis and treatment of venous thromboembolism and other thrombotic diseases. Handb Exp Pharmacol 2012; 207: 179-209.

4 Nader HB, Chavante SF, dos-Santos EA et al. Heparan sulfates and heparins: similar compounds performing the same functions in vertebrates and invertebrates? Braz J Med Biol Res 1999,32:529-38.

5 Ledin J, Staatz W, Li JP et al. Heparan sulfate structure in mice with genetically modified heparan sulfate production. $J$ Biol Chem 2004; 279: 42732-41.

6 Maccarana M, Sakura Y, Tawada A, Yoshida K, Lindahl U. Domain structure of heparan sulfates from bovine organs. J Biol Chem 1996; 271: 17804-10.

7 Kjellen L, Lindahl U. Proteoglycans: structures and interactions. Annu Rev Biochem 1991; 60: 443-75.

8 Bernfield M, Gotte M, Park PW et al. Functions of cell surface heparan sulfate proteoglycans. Annu Rev Biochem 1999; 68: 729-77.

9 Bishop JR, Schuksz M, Esko JD. Heparan sulphate proteoglycans fine-tune mammalian physiology. Nature 2007; 446: $1030-7$.

10 Lindahl U, Li JP. Interactions between heparan sulfate and proteins-design and functional implications. Int Rev Cell Mol Biol 2009; 276: 105-59.

11 Esko JD, Lindahl U. Molecular diversity of heparan sulfate. J Clin Invest 2001; 108: 169-73.

12 Lindahl U, Kusche-Gullberg M, Kjellen L. Regulated diversity of heparan sulfate. $J$ Biol Chem 1998; 273: 24979-82.

13 Esko JD, Kimata K, Lindahl U. Proteoglycans and Sulfated Glycosaminoglycans. In: Varki A, Cummings RD, Esko JD et al. , eds. Essentials of Glycobiology, 2nd edn. NewYork, NY: Cold Spring Harbor, 2009; 229-48.

14 Kolset SO, Pejler G. Serglycin: a structural and functional chameleon with wide impact on immune cells. $J$ Immunol 2011; 187: 4927-33.
15 Vogt AM, Winter G, Wahlgren M, Spillmann D. Heparan sulphate identified on human erythrocytes: a Plasmodium falciparum receptor. Biochem J 2004; 381: 593-7.

16 Casu B, Lindahl U. Structure and biological interactions of heparin and heparan sulfate. Adv Carbohydr Chem Biochem 2001; 57: 159-206.

17 Westling C, Lindahl U. Location of N-unsubstituted glucosamine residues in heparan sulfate. J Biol Chem 2002; 277: 49247-55.

18 Ai X, Do AT, Kusche-Gullberg M, Lindahl U, Lu K, Emerson $\mathrm{CP}$ Jr. Substrate specificity and domain functions of extracellular heparan sulfate 6-O-endosulfatases, QSulf1 and QSulf2. J Biol Chem 2006; 281: 4969-76.

19 Kreuger J, Kjellen L Heparan sulfate biosynthesis-regulation and variability. J Histochem Cytochem 2012, 60: 898-907.

20 Gallagher JT, Walker A. Molecular distinctions between heparan sulphate and heparin. Analysis of sulphation patterns indicates that heparan sulphate and heparin are separate families of $\mathrm{N}$-sulphated polysaccharides. Biochem $J$ 1985; 230: 665-74

21 Lyon M, Deakin JA, Gallagher JT. Liver heparan sulfate structure. A novel molecular design. J Biol Chem 1994; 269: $11208-15$.

22 Tumova S, Woods A, Couchman JR. Heparan sulfate chains from glypican and syndecans bind the Hep II domain of fibronectin similarly despite minor structural differences. $J$ Biol Chem 2000; 275: 9410-7.

23 Morii E, Ogihara H, Oboki K et al. Inhibitory effect of the mi transcription factor encoded by the mutant mi allele on GA binding protein-mediated transcript expression in mouse mast cells. Blood 2001; 97: 3032-9.

24 Grobe K, Esko JD. Regulated translation of heparan sulfate $\mathrm{N}$-acetylglucosamine $\mathrm{N}$-deacetylase/n-sulfotransferase isozymes by structured 5 '-untranslated regions and internal ribosome entry sites. J Biol Chem 2002; 277: 30699-706.

25 Kobayashi S, Morimoto K, Shimizu T, Takahashi M, Kurosawa H, Shirasawa T. Association of EXT1 and EXT2, hereditary multiple exostoses gene products, in Golgi apparatus. Biochem Biophys Res Commun 2000; 268: 860-7.

26 McCormick C, Duncan G, Goutsos KT, Tufaro F. The putative tumor suppressors EXT1 and EXT2 form a stable complex that accumulates in the Golgi apparatus and catalyzes the synthesis of heparan sulfate. Proc Natl Acad Sci USA 2000; 97: 668-73.

27 Pinhal MA, Smith B, Olson S, Aikawa J, Kimata K, Esko JD. Enzyme interactions in heparan sulfate biosynthesis: uronosyl 5-epimerase and 2-O-sulfotransferase interact in vivo. Proc Natl Acad Sci USA 2001; 98: 12984-9.

28 Schwartz NB, Roden L, Dorfman A. Biosynthesis of chondroitin sulfate: interaction between xylosyltransferase and galactosyltransferase. Biochem Biophys Res Commun 1974; 56: $717-24$

29 Presto J, Thuveson M, Carlsson P et al. Heparan sulfate biosynthesis enzymes EXT1 and EXT2 affect NDST1 expression and heparan sulfate sulfation. Proc Natl Acad Sci USA 2008; 105: 4751-6.

30 Esko JD, Selleck SB. Order out of chaos: assembly of ligand binding sites in heparan sulfate. Annu Rev Biochem 2002; 71: 435-71.

31 Robinson HC, Horner AA, Hook M, Ogren S, Lindahl U. A proteoglycan form of heparin and its degradation to singlechain molecules. J Biol Chem 1978; 253: 6687-93. 
32 Oldberg A, Kjellen L, Hook M. Cell-surface heparan sulfate. Isolation and characterization of a proteoglycan from rat liver membranes. J Biol Chem 1979; 254: 8505-10.

33 Lyon M, Gallagher JT. Hepatocyte growth factor/scatter factor: a heparan sulphate-binding pleiotropic growth factor. Biochem Soc Trans 1994; 22: 365-70.

34 Jacobsson KG, Lindahl U. Degradation of heparin proteoglycan in cultured mouse mastocytoma cells. Biochem $J$ 1987; 246: 409-15.

35 Guerrini M, Bisio A Low-molecular-weight heparins: differential characterization/physical characterization. Handb Exp Pharmacol 2012; 207:127-57.

36 Petitou M, Casu B, Lindahl U. 1976-1983, a critical period in the history of heparin: the discovery of the antithrombin binding site. Biochimie 2003; 85: 83-9.

37 Bourin MC, Lindahl U. Glycosaminoglycans and the regulation of blood coagulation. Biochem $J$ 1993; 289: 313-30.

38 Rosenberg RD, Shworak NW, Liu J, Schwartz JJ, Zhang L. Heparan sulfate proteoglycans of the cardiovascular system. Specific structures emerge but how is synthesis regulated? $J$ Clin Invest 1997; 100: S67-75.

39 Gama CI, Tully SE, Sotogaku N et al. Sulfation patterns of glycosaminoglycans encode molecular recognition and activity. Nat Chem Biol 2006; 2: 467-73.

40 Kreuger J, Spillmann D, Li JP, Lindahl U. Interactions between heparan sulfate and proteins: the concept of specificity. J Cell Biol 2006; 174: 323-7.

41 Jastrebova N, Vanwildemeersch M, Lindahl U, Spillmann D. Heparan sulfate domain organization and sulfation modulate FGF-induced cell signaling. J Biol Chem 2010; 285: 26842-51.

42 Mulloy B Structure and physicochemical characterisation of heparin. Handb Exp Pharmacol 2012; 207: 77-98.

43 Langeslay DJ, Young RP, Beni S, Beecher CN, Mueller LJ, Larive CK. Sulfamate proton solvent exchange in heparin oligosaccharides: evidence for a persistent hydrogen bond in the antithrombin-binding pentasaccharide Arixtra. Glycobiology 2012; 22: 1173-82.

44 Olson ST, Richard B, Izaguirre G, Schedin-Weiss S, Gettins PG. Molecular mechanisms of antithrombin-heparin regulation of blood clotting proteinases. A paradigm for understanding proteinase regulation by serpin family protein proteinase inhibitors. Biochimie 2010; 92: 1587-96.

45 Selleck SB Shedding light on the distinct functions of proteoglycans. Sci STKE 2006, 2006:pe17.

46 Pellegrini L, Burke DF, von Delft F, Mulloy B, Blundell TL. Crystal structure of fibroblast growth factor receptor ectodomain bound to ligand and heparin. Nature 2000; 407: 1029-34.

47 Mohammadi M, Olsen SK, Ibrahimi OA. Structural basis for fibroblast growth factor receptor activation. Cytokine Growth Factor Rev 2005; 16: 107-37.

48 Ogren S, Lindahl U. Cleavage of macromolecular heparin by an enzyme from mouse mastocytoma. J Biol Chem 1975; 250: 2690-7.

49 Ogren S, Lindahl U. Metabolism of macromolecular heparin in mouse neoplastic mast cells. Biochem $J$ 1976; 154: 60511.

50 Oldberg A, Heldin $\mathrm{CH}$, Wasteson A, Busch C, Hook M. Characterization of a platelet endoglycosidase degrading heparin-like polysaccharides. Biochemistry 1980; 19: 575562.
51 Gong F, Jemth P. Escobar Galvis ML, Vlodavsky I, Horner A, Lindahl U, et al. Processing of macromolecular heparin by heparanase. J Biol Chem 2003; 278: 35152-8.

52 Vlodavsky I, Ilan N, Naggi A, Casu B. Heparanase: structure, biological functions, and inhibition by heparin-derived mimetics of heparan sulfate. Curr Pharm Des 2007; 13: 2057 73.

53 Wang B, Jia J, Zhang X et al. Heparanase affects secretory granule homeostasis of murine mast cells through degrading heparin. J Allergy Clin Immunol 2011; 128: 1310-1317.e8..

54 Zcharia E, Metzger S, Chajek-Shaul $\mathrm{T}$ et al. Transgenic expression of mammalian heparanase uncovers physiological functions of heparan sulfate in tissue morphogenesis, vascularization, and feeding behavior. FASEB $J$ 2004; 18: 252-63.

55 Zcharia E, Jia J, Zhang X et al. Newly generated heparanase knock-out mice unravel co-regulation of heparanase and matrix metalloproteinases. PLOS ONE 2009; 4: e5181.

56 Lin X, Wei G, Shi Z et al. Disruption of gastrulation and heparan sulfate biosynthesis in EXT1-deficient mice. Dev Biol 2000; 224: 299-311.

57 Stickens D, Zak BM, Rougier N, Esko JD, Werb Z. Mice deficient in Ext2 lack heparan sulfate and develop exostoses. Development 2005; 132: 5055-68.

58 Holmborn K, Ledin J, Smeds E, Eriksson I, Kusche-Gullberg M, Kjellen L. Heparan sulfate synthesized by mouse embryonic stem cells deficient in NDST1 and NDST2 is 6-Osulfated but contains no N-sulfate groups. J Biol Chem 2004; 279: 42355-8.

59 Ringvall M, Ledin J, Holmborn K et al. Defective heparan sulfate biosynthesis and neonatal lethality in mice lacking N-deacetylase/N-sulfotransferase-1. J Biol Chem 2000; 275: 25926-30.

60 Fan G, Xiao L, Cheng L, Wang X, Sun B, Hu G. Targeted disruption of NDST-1 gene leads to pulmonary hypoplasia and neonatal respiratory distress in mice. FEBS Lett 2000; 467: 7-11.

61 Ringvall M, Kjellen L. Mice deficient in heparan sulfate Ndeacetylase/N-sulfotransferase 1. Prog Mol Biol Transl Sci 2010; 93: 35-58.

62 Forsberg E, Pejler G, Ringvall M et al. Abnormal mast cells in mice deficient in a heparin-synthesizing enzyme. Nature 1999; 400: 773-6.

63 Humphries DE, Wong GW, Friend DS et al. Heparin is essential for the storage of specific granule proteases in mast cells. Nature 1999; 400: 769-72.

64 Li JP, Gong F, Hagner-McWhirter A et al. Targeted disruption of a murine glucuronyl C5-epimerase gene results in heparan sulfate lacking L-iduronic acid and in neonatal lethality. J Biol Chem 2003; 278: 28363-6.

$65 \mathrm{Li}$ JP. Glucuronyl C5-epimerase an enzyme converting glucuronic acid to iduronic acid in heparan sulfate/heparin biosynthesis. Prog Mol Biol Transl Sci 2010; 93: 59-78.

66 Bullock SL, Fletcher JM, Beddington RS, Wilson VA. Renal agenesis in mice homozygous for a gene trap mutation in the gene encoding heparan sulfate 2-sulfotransferase. Genes Dev 1998; 12: 1894-906.

67 Habuchi H, Nagai N, Sugaya N, Atsumi F, Stevens RL, Kimata K. Mice deficient in heparan sulfate 6-O-sulfotransferase-1 exhibit defective heparan sulfate biosynthesis, abnormal placentation, and late embryonic lethality. $J$ Biol Chem 2007; 282: 15578-88. 
68 Habuchi H, Kimata K. Mice deficient in heparan sulfate 6-Osulfotransferase-1. Prog Mol Biol Transl Sci 2010; 93: 79111.

69 Couchman JR. Transmembrane signaling proteoglycans. Annu Rev Cell Dev Biol 2010; 26: 89-114.

70 Iozzo RV, Zoeller JJ, Nystrom A. Basement membrane proteoglycans: modulators Par Excellence of cancer growth and angiogenesis. Mol Cells 2009; 27: 503-13.

71 Whitelock J, Melrose J. Heparan sulfate proteoglycans in healthy and diseased systems. Wiley Interdiscip Rev Syst Biol Med 2011; 3: 739-51.

72 Koziel L, Kunath M, Kelly OG, Vortkamp A. Ext1-dependent heparan sulfate regulates the range of Ihh signaling during endochondral ossification. Dev Cell 2004; 6: 801-13.

73 Takei Y, Takigahira M, Mihara K, Tarumi Y, Yanagihara K. The metastasis-associated microRNA miR-516a-3p is a novel therapeutic target for inhibiting peritoneal dissemination of human scirrhous gastric cancer. Cancer Res 2011; 71: 1442-53.

74 O'Connell MP, Billings PC, Fiori JL et al. HSPG modulation of BMP signaling in fibrodysplasia ossificans progressiva cells. J Cell Biochem 2007; 102: 1493-503.

75 Folkman J. The role of angiogenesis in tumor growth. Semin Cancer Biol 1992; 3: 65-71.

76 Claesson-Welsh L. Blood vessels as targets in tumor therapy. Ups J Med Sci 2012; 117: 178-86.

77 Fuster MM, Wang L, Castagnola J et al. Genetic alteration of endothelial heparan sulfate selectively inhibits tumor angiogenesis. J Cell Biol 2007; 177: 539-49.

78 Jastrebova N, Vanwildemeersch M, Rapraeger AC, GimenezGallego G, Lindahl U, Spillmann D. Heparan sulfate-related oligosaccharides in ternary complex formation with fibroblast growth factors 1 and 2 and their receptors. $J$ Biol Chem 2006; 281: 26884-92.

79 Rolny C, Spillmann D, Lindahl U, Claesson-Welsh L. Heparin amplifies platelet-derived growth factor (PDGF)- BBinduced PDGF alpha -receptor but not PDGF beta -receptor tyrosine phosphorylation in heparan sulfate-deficient cells. Effects on signal transduction and biological responses. $J$ Biol Chem 2002; 277: 19315-21.

80 Le Jan S, Hayashi M, Kasza $Z$ et al. Functional overlap between chondroitin and heparan sulfate proteoglycans during VEGF-induced sprouting angiogenesis. Arterioscler Thromb Vasc Biol 2012; 32: 1255-63.

81 Selleck SB. Signaling from across the way: transactivation of VEGF receptors by HSPGs. Mol Cell 2006; 22: 431-2.

82 Jakobsson L, Kreuger J, Holmborn K et al. Heparan sulfate in trans potentiates VEGFR-mediated angiogenesis. Dev Cell 2006; 10: 625-34.

$83 \mathrm{Xu}$ D, Fuster MM, Lawrence R, Esko JD. Heparan sulfate regulates VEGF165- and VEGF121-mediated vascular hyperpermeability. $J$ Biol Chem 2011; 286: 737-45.

84 Bendas G, Borsig L. Cancer cell adhesion and metastasis: selectins, integrins, and the inhibitory potential of heparins. Int $J$ Cell Biol 2012; 2012: 676731.

85 Kreuger J, Matsumoto T, Vanwildemeersch M et al. Role of heparan sulfate domain organization in endostatin inhibition of endothelial cell function. EMBO J 2002; 21: 630311.

86 Bramono DS, Murali S, Rai B et al. Bone marrow-derived heparan sulfate potentiates the osteogenic activity of bone morphogenetic protein-2 (BMP-2). Bone 2012; 50: 954-64.
87 Westermark P. Aspects on human amyloid forms and their fibril polypeptides. FEBS J 2005; 272: 5942-9.

88 Kisilevsky R, Ancsin JB, Szarek WA, Petanceska S. Heparan sulfate as a therapeutic target in amyloidogenesis: prospects and possible complications. Amyloid 2007; 14: 21-32.

89 Liu IH, Uversky VN, Munishkina LA, Fink AL, Halfter W, Cole GJ. Agrin binds alpha-synuclein and modulates alpha-synuclein fibrillation. Glycobiology 2005; 15: 132031.

90 Noborn F, O'Callaghan P, Hermansson E et al. Heparan sulfate/heparin promotes transthyretin fibrillization through selective binding to a basic motif in the protein. Proc Natl Acad Sci USA 2011; 108: 5584-9.

91 Elimova E, Kisilevsky R, Ancsin JB. Heparan sulfate promotes the aggregation of HDL-associated serum amyloid A: evidence for a proamyloidogenic histidine molecular switch. FASEB J 2009; 23: 3436-48.

92 O'Callaghan P, Sandwall E, Li JP et al. Heparan sulfate accumulation with Abeta deposits in Alzheimer's disease and Tg2576 mice is contributed by glial cells. Brain Pathol 2008; 18: 548-61.

93 Sandwall E, O'Callaghan P, Zhang X, Lindahl U, Lannfelt L, Li JP. Heparan sulfate mediates amyloid-beta internalization and cytotoxicity. Glycobiology 2010; 20: 533-41.

94 Scholefield Z, Yates EA, Wayne G, Amour A, McDowell W, Turnbull JE. Heparan sulfate regulates amyloid precursor protein processing by BACE1, the Alzheimer's beta-secretase. J Cell Biol 2003; 163: 97-107.

95 Lindahl B, Lindahl U. Amyloid-specific heparan sulfate from human liver and spleen. J Biol Chem 1997; 272: 26091-4.

$96 \mathrm{Li} \mathrm{JP}$, Galvis ML, Gong $\mathrm{F}$ et al. In vivo fragmentation of heparan sulfate by heparanase overexpression renders mice resistant to amyloid protein A amyloidosis. Proc Natl Acad Sci USA 2005; 102: 6473-7.

97 Escobar GalvisML, Jia J, Zhang $\mathrm{X}$ et al. Transgenic or tumor-induced expression of heparanase upregulates sulfation of heparan sulfate. Nat Chem Biol 2007, 3:773-8.

98 Tran-Lundmark K, Tran PK, Paulsson-Berne G et al. Heparan sulfate in perlecan promotes mouse atherosclerosis: roles in lipid permeability, lipid retention, and smooth muscle cell proliferation. Circ Res 2008; 103: 43-52.

99 Iivonen S, Helisalmi S, Mannermaa A et al. Heparan sulfate proteoglycan 2 polymorphism in Alzheimer's disease and correlation with neuropathology. Neurosci Lett 2003; 352: 146-50.

100 MacArthur JM, Bishop JR, Stanford KI et al. Liver heparan sulfate proteoglycans mediate clearance of triglyceride-rich lipoproteins independently of LDL receptor family members. $J$ Clin Invest 2007; 117: 153-64.

101 Foley EM, Esko JD. Hepatic heparan sulfate proteoglycans and endocytic clearance of triglyceride-rich lipoproteins. Prog Mol Biol Transl Sci 2010; 93: 213-33.

102 Noborn F, Ancsin JB, Ubhayasekera W, Kisilevsky R, Li JP. Heparan sulfate dissociates serum amyloid A (SAA) from acute-phase high-density lipoprotein, promoting SAA aggregation. J Biol Chem 2012; 287: 25669-77.

103 Proudfoot AE. The biological relevance of chemokine-proteoglycan interactions. Biochem Soc Trans 2006; 34: 422-6.

104 Laguri C, Arenzana-Seisdedos F, Lortat-Jacob H. Relationships between glycosaminoglycan and receptor binding sites in chemokines-the CXCL12 example. Carbohydr Res 2008; 343: 2018-23. 
105 Lortat-Jacob H. The molecular basis and functional implications of chemokine interactions with heparan sulphate. Curr Opin Struct Biol 2009; 19: 543-8.

106 Hamel DJ, Sielaff I, Proudfoot AE, Handel TM. Chapter 4. Interactions of chemokines with glycosaminoglycans. Methods Enzymol 2009; 461: 71-102.

107 Spillmann D, Witt D, Lindahl U. Defining the interleukin-8binding domain of heparan sulfate. J Biol Chem 1998; 273: 15487-93.

108 Wang L, Fuster M, Sriramarao P, Esko JD. Endothelial heparan sulfate deficiency impairs L-selectin- and chemokine-mediated neutrophil trafficking during inflammatory responses. Nat Immunol 2005; 6: 902-10.

109 Stevenson JL, Varki A, Borsig L. Heparin attenuates metastasis mainly due to inhibition of P- and L-selectin, but nonanticoagulant heparins can have additional effects. Thromb Res 2007; 120 (Supp1 2): S107-11.

110 Zhang X, Wang B, O'Callaghan $\mathrm{P}$ et al. Heparanase overexpression impairs inflammatory response and macrophagemediated clearance of amyloid-beta in murine brain. Acta Neuropathol 2012; 124: 465-78.

111 Mu E, Ding R, An X, Li X, Chen S, Ma X. Heparin attenuates lipopolysaccharide-induced acute lung injury by inhibiting nitric oxide synthase and TGF-beta/Smad signaling pathway. Thromb Res 2012; 129: 479-85.

112 Chande N, MacDonald JK, Wang JJ, McDonald JW. Unfractionated or low molecular weight heparin for induction of remission in ulcerative colitis: a Cochrane inflammatory bowel disease and functional bowel disorders systematic review of randomized trials. Inflamm Bowel Dis 2011; 17: 1979-86.

113 Spillmann D. Heparan sulfate: anchor for viral intruders? Biochimie 2001; 83: 811-7.

114 Rue CA, Ryan P. Characterization of pseudorabies virus glycoprotein $\mathrm{C}$ attachment to heparan sulfate proteoglycans. $J$ Gen Virol 2002; 83: 301-9.

115 Feyzi E, Trybala E, Bergstrom T, Lindahl U, Spillmann D. Structural requirement of heparan sulfate for interaction with herpes simplex virus type 1 virions and isolated glycoprotein C. J Biol Chem 1997; 272: 24850-7.

116 Shukla D, Liu J, Blaiklock P et al. A novel role for 3-Osulfated heparan sulfate in herpes simplex virus 1 entry. Cell 1999; 99: 13-22.

117 Knappe M, Bodevin S, Selinka HC et al. Surface-exposed amino acid residues of HPV16 L1 protein mediating interaction with cell surface heparan sulfate. J Biol Chem 2007; 282: $27913-22$.

118 Schmidtke M, Karger A, Meerbach A, Egerer R, Stelzner A, Makarov V. Binding of a N, N'-bisheteryl derivative of dispirotripiperazine to heparan sulfate residues on the cell surface specifically prevents infection of viruses from different families. Virology 2003; 311: 134-43.

119 Urbinati C, Nicoli S, Giacca M et al. HIV-1 Tat and heparan sulfate proteoglycan interaction: a novel mechanism of lymphocyte adhesion and migration across the endothelium. Blood 2009; 114: 3335-42.

120 WuDunn D, Spear PG. Initial interaction of herpes simplex virus with cells is binding to heparan sulfate. J Virol 1989; 63: $52-8$.

121 Lycke E, Johansson M, Svennerholm B, Lindahl U. Binding of herpes simplex virus to cellular heparan sulphate, an initial step in the adsorption process. J Gen Virol 1991; 72: 1131-7.
122 McCormick C, Leduc Y, Martindale D et al. The putative tumour suppressor EXT1 alters the expression of cellsurface hapran sulfate. Nat Genet 1998; 19: 158-61.

123 Lind T, Tufaro F, McCormick C, Lindahl U, Lidholt K. The putative tumor suppressors EXT1 and EXT2 are glycosyltransferases required for the biosynthesis of heparan sulfate. J Biol Chem 1998; 273: 26265-8.

124 Liu J, Shworak NW, Sinay P et al. Expression of heparan sulfate D-glucosaminyl 3-O-sulfotransferase isoforms reveals novel substrate specificities. J Biol Chem 1999; 274: 5185-92.

125 Copeland R, Balasubramaniam A, Tiwari V et al. Using a 3-Osulfated heparin octasaccharide to inhibit the entry of herpes simplex virus type 1. Biochemistry 2008; 47: 5774-83.

126 Vogt AM, Pettersson F, Moll K et al. Release of sequestered malaria parasites upon injection of a glycosaminoglycan. PLoS Pathog 2006; 2: e100.

127 Munir M, Tjandra H, Rampengan TH, Mustadjab I, Wulur FH. Heparin in the treatment of cerebral malaria. Paediatr Indones 1980; 20: 47-50.

128 Chen Q, Barragan A, Fernandez V et al. Identification of Plasmodium falciparum erythrocyte membrane protein 1 (PfEMP1) as the rosetting ligand of the malaria parasite P. falciparum. J Exp Med 1998; 187: 15-23.

129 Kahn F, Morgelin M, Shannon O et al. Antibodies against a surface protein of Streptococcus pyogenes promote a pathological inflammatory response. PLoS Pathog 2008; 4: e1000149.

130 Olofsson AM, Vestberg M, Herwald H et al. Heparin-binding protein targeted to mitochondrial compartments protects endothelial cells from apoptosis. J Clin Invest 1999; 104: 885-94.

131 Gautam N, Olofsson AM, Herwald $\mathrm{H}$ et al. Heparin-binding protein (HBP/CAP37): a missing link in neutrophil-evoked alteration of vascular permeability. Nat Med 2001; 7: 1123-7.

132 Andersson E, Rydengard V, Sonesson A, Morgelin M, Bjorck L, Schmidtchen A. Antimicrobial activities of heparin-binding peptides. Eur J Biochem 2004; 271: 1219-26.

133 Filmus J, Capurro M. The role of glypican-3 in the regulation of body size and cancer. Cell Cycle 2008; 7: 2787-90.

134 Campos-Xavier AB, Martinet D, Bateman J et al. Mutations in the heparan-sulfate proteoglycan glypican 6 (GPC6) impair endochondral ossification and cause recessive omodysplasia. Am J Hum Genet 2009; 84: 760-70.

135 Okamoto $\mathrm{K}$, Tokunaga $\mathrm{K}$, Doi $\mathrm{K}$ et al. Common variation in GPC5 is associated with acquired nephrotic syndrome. Nat Genet 2011,43:459-63.

136 Arikawa-Hirasawa E, Wilcox WR, Le AH et al. Dyssegmental dysplasia, Silverman-Handmaker type, is caused by functional null mutations of the perlecan gene. Nat Genet 2001; 27: 431-4.

137 Rieubland C, Jacquemont S, Mittaz L et al. Phenotypic and molecular characterization of a novel case of dyssegmental dysplasia, Silverman-Handmaker type. Eur J Med Genet 2010; 53: 294-8.

138 Nicole S, Davoine CS, Topaloglu H et al. Perlecan, the major proteoglycan of basement membranes, is altered in patients with Schwartz-Jampel syndrome (chondrodystrophic myotonia). Nat Genet 2000; 26: 480-3.

139 Huze C, Bauche S, Richard P et al. Identification of an agrin mutation that causes congenital myasthenia and affects synapse function. Am J Hum Genet 2009; 85: 155-67.

140 Sertie AL, Sossi V, Camargo AA, Zatz M, Brahe C, PassosBueno MR. Collagen XVIII, containing an endogenous 
inhibitor of angiogenesis and tumor growth, plays a critical role in the maintenance of retinal structure and in neural tube closure (Knobloch syndrome). Hum Mol Genet 2000,9:2051-8.

141 Cluff AH, Bystrom B, Klimaviciute A et al. Prolonged labour associated with lower expression of syndecan 3 and connexin 43 in human uterine tissue. Reprod Biol Endocrinol 2006; 4: 24.

142 Ekman-Ordeberg G, Hellgren M, Akerud A et al. Low molecular weight heparin stimulates myometrial contractility and cervical remodeling in vitro. Acta Obstet Gynecol Scand 2009; 88: 984-9.

143 Lawrence R, Brown JR, Al-Mafraji K et al. Disease-specific non-reducing end carbohydrate biomarkers for mucopolysaccharidoses. Nat Chem Biol 2012; 8: 197-204.

144 Holley RJ, Deligny A, Wei W et al. Mucopolysaccharidosis type I, unique structure of accumulated heparan sulfate and increased N-sulfotransferase activity in mice lacking alpha1-iduronidase. J Biol Chem 2011; 286: 37515-24.

145 Hemsley KM, Hopwood JJ. Emerging therapies for neurodegenerative lysosomal storage disorders - from concept to reality. J Inherit Metab Dis 2011; 34: 1003-12.

146 Clarke LA. The mucopolysaccharidoses: a success of molecular medicine. Expert Rev Mol Med 2008; 10: e1.

147 Neufeld EF, Meunzer, J. The Mucopolysaccharidoses. In: Scriver CR, Beaudet AL et al. , eds. The Molecular Basis of Inherited Disease. New York: McGraw-Hill, 2001; 3421-52.

148 Kjellen L, Bielefeld D, Hook M. Reduced sulfation of liver heparan sulfate in experimentally diabetic rats. Diabetes 1983; 32: 337-42.

149 Zak BM, Schuksz M, Koyama E et al. Compound heterozygous loss of Ext1 and Ext2 is sufficient for formation of multiple exostoses in mouse ribs and long bones. Bone 2011; 48: 979-87.

150 Osterholm C, Barczyk MM, Busse M, Gronning M, Reed RK, Kusche-Gullberg M. Mutation in the heparan sulfate biosynthesis enzyme EXT1 influences growth factor signaling and fibroblast interactions with the extracellular matrix. $J$ Biol Chem 2009; 284: 34935-43.

151 Irie F, Badie-Mahdavi H, Yamaguchi Y. Autism-like sociocommunicative deficits and stereotypies in mice lacking heparan sulfate. Proc Natl Acad Sci USA 2012; 109: 5052-6.

152 Tornberg J, Sykiotis GP, Keefe K et al. Heparan sulfate 6-Osulfotransferase 1 , a gene involved in extracellular sugar modifications, is mutated in patients with idiopathic hypogonadotrophic hypogonadism. Proc Natl Acad Sci USA 2011; 108: 11524-9.

153 HajMohammadi S, Enjyoji K, Princivalle M et al. Normal levels of anticoagulant heparan sulfate are not essential for normal hemostasis. J Clin Invest 2003; 111: 989-99.

154 Lindahl U, Kolset SO, Bogwald J, Osterud B, Seljelid R. Studies, with a luminogenic peptide substrate, on blood coagulation factor $\mathrm{X} / \mathrm{Xa}$ produced by mouse peritoneal macrophages. Biochem J 1982; 206: 231-7.

155 Vlodavsky I, Beckhove P, Lerner I et al. Significance of heparanase in cancer and inflammation. Cancer Microenviron 2012; 5: 115-32.
$156 \mathrm{Li} \mathrm{RW}$, Freeman C, Yu D et al. Dramatic regulation of heparanase activity and angiogenesis gene expression in synovium from patients with rheumatoid arthritis. Arthritis Rheum 2008; 58: 1590-600.

157 Ziolkowski AF, Popp SK, Freeman C, Parish CR, Simeonovic $\mathrm{CJ}$. Heparan sulfate and heparanase play key roles in mouse beta cell survival and autoimmune diabetes. $J$ Clin Invest 2012; 122: 132-41.

158 Karlsson-Lindahl L, Schmidt L, Haage D et al. Heparanase affects food intake and regulates energy balance in mice. PLOS ONE 2012; 7: e34313.

159 Reizes O, Lincecum J, Wang $Z$ et al. Transgenic expression of syndecan-1 uncovers a physiological control of feeding behavior by syndecan-3. Cell 2001; 106: 105-16.

160 Lindahl U. Heparan sulfate-protein interactions-a concept for drug design? Thromb Haemost 2007; 98: 109-15.

161 Petitou M, Nancy-Portebois V, Dubreucq G et al. From heparin to EP217609: the long way to a new pentasaccharide-based neutralisable anticoagulant with an unprecedented pharmacological profile. Thromb Haemost 2009; 102: 804-10.

162 Di Giacomo F, Lewandowski D, Cabannes E et al. Heparan sulfate mimetics can efficiently mobilize long-term hematopoietic stem cells. Haematologica 2012; 97: 491-9.

163 Belting M, Borsig L, Fuster MM et al. Tumor attenuation by combined heparan sulfate and polyamine depletion. Proc Natl Acad Sci USA 2002; 99: 371-6.

164 Kisilevsky R, Szarek WA, Ancsin J, Vohra R, Li Z, Marone S. Novel glycosaminoglycan precursors as antiamyloid agents: part IV. J Mol Neurosci 2004; 24: 167-72.

165 Schuksz M, Fuster MM, Brown JR et al. Surfen, a small molecule antagonist of heparan sulfate. Proc Natl Acad Sci USA 2008; 105: 13075-80.

166 Kisilevsky R, Lemieux LJ, Fraser PE, Kong X, Hultin PG, Szarek WA. Arresting amyloidosis in vivo using smallmolecule anionic sulphonates or sulphates: implications for Alzheimer's disease. Nat Med 1995; 1: 143-8.

167 Adage T, Piccinini AM, Falsone A et al. Structure-based design of decoy chemokines as a way to explore the pharmacological potential of glycosaminoglycans. Br J Pharmacol 2012, 167: 1195-205.

168 de Paz JL, Seeberger PH. Deciphering the glycosaminoglycan code with the help of microarrays. Mol BioSyst 2008; 4: 707-11.

169 Naggi A, Casu B, Perez M et al. Modulation of the heparanase-inhibiting activity of heparin through selective desulfation, graded $\mathrm{N}$-acetylation, and glycol splitting. $J$ Biol Chem 2005; 280: 12103-13.

170 Levidiotis V, Freeman C, Punler M et al. A synthetic heparanase inhibitor reduces proteinuria in passive Heymann nephritis. J Am Soc Nephrol 2004; 15: 2882-92.

Correspondence: Ulf Lindahl, Department of Medical Biochemistry and Microbiology, Uppsala University, SE-751 23 Uppsala, Sweden.

(fax: +46 18 4714673; e-mail: ulf.lindahl@imbim.uu.se). 